
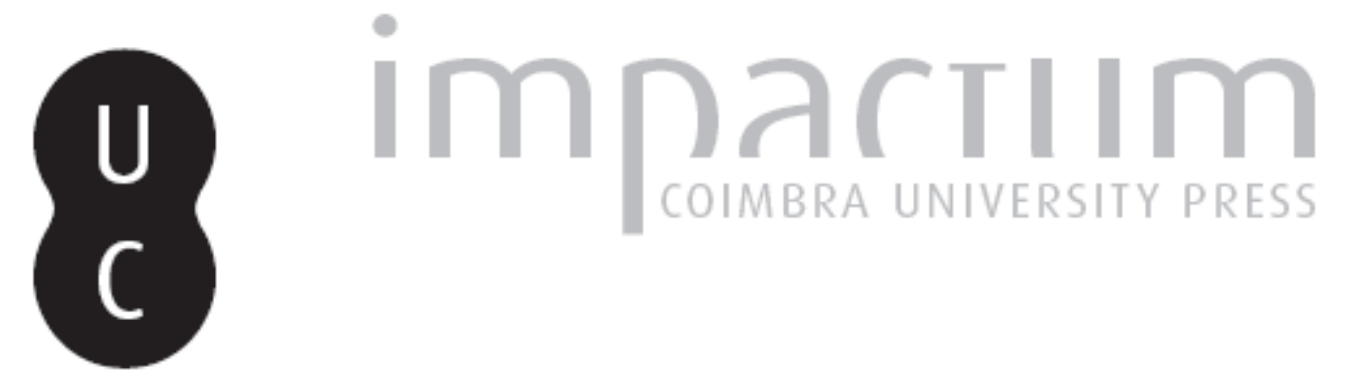

\title{
Apontamentos sobre a arquitectura religiosa do século XX em Portugal
}

\section{Autor(es): Silva, Cidália}

Publicado por: Editorial do Departamento de Arquitetura

URL persistente:

URI:http://hdl.handle.net/10316.2/37488

DOI:

DOI:http://dx.doi.org/10.14195/0874-6168_5_8

Accessed : $\quad$ 26-Apr-2023 11:07:15

A navegação consulta e descarregamento dos títulos inseridos nas Bibliotecas Digitais UC Digitalis, UC Pombalina e UC Impactum, pressupõem a aceitação plena e sem reservas dos Termos e Condições de Uso destas Bibliotecas Digitais, disponíveis em https://digitalis.uc.pt/pt-pt/termos.

Conforme exposto nos referidos Termos e Condições de Uso, o descarregamento de títulos de acesso restrito requer uma licença válida de autorização devendo o utilizador aceder ao(s) documento(s) a partir de um endereço de IP da instituição detentora da supramencionada licença.

Ao utilizador é apenas permitido o descarregamento para uso pessoal, pelo que o emprego do(s) título(s) descarregado(s) para outro fim, designadamente comercial, carece de autorização do respetivo autor ou editor da obra.

Na medida em que todas as obras da UC Digitalis se encontram protegidas pelo Código do Direito de Autor e Direitos Conexos e demais legislação aplicável, toda a cópia, parcial ou total, deste documento, nos casos em que é legalmente admitida, deverá conter ou fazer-se acompanhar por este aviso. 


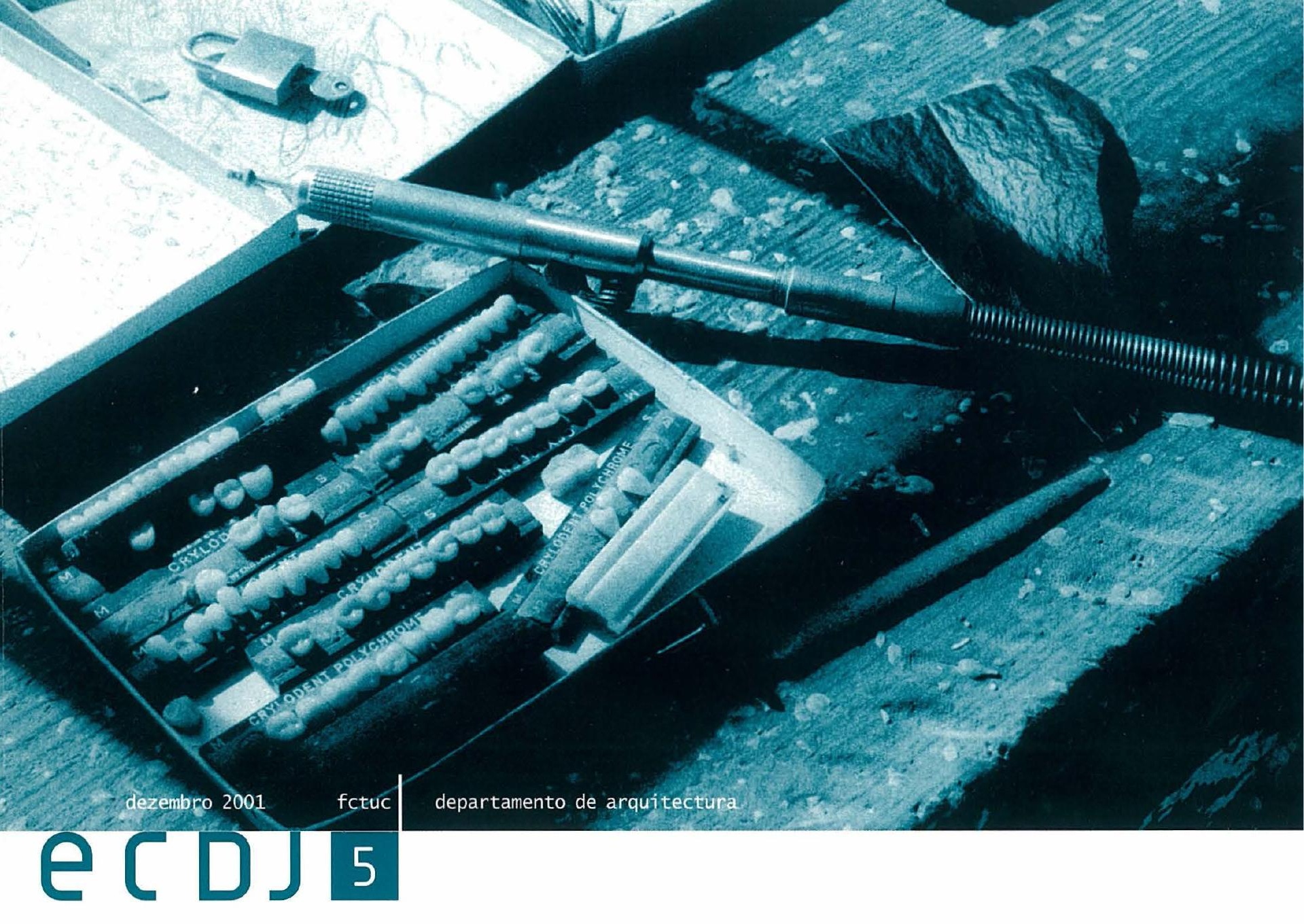

\section{investigação em arquitectura [?]}

George Teyssot

Paulo Providência | Mário Krüger | Wałter Rossa | António olaio

Outra abertura adelino gonçałves

Sti11Life, duração e abandono na obra de john hejduk francisco ferreira

Onde há fogo, nós levamos gasolina pedro bandeira

Apontamentos sobre a arquitectura religiosa do séc. XX em Portugal cidália silva

o desafio ecológico luís pinto faria

Pescada de rabo na boca patrícia miguel carvalho

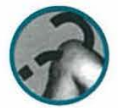




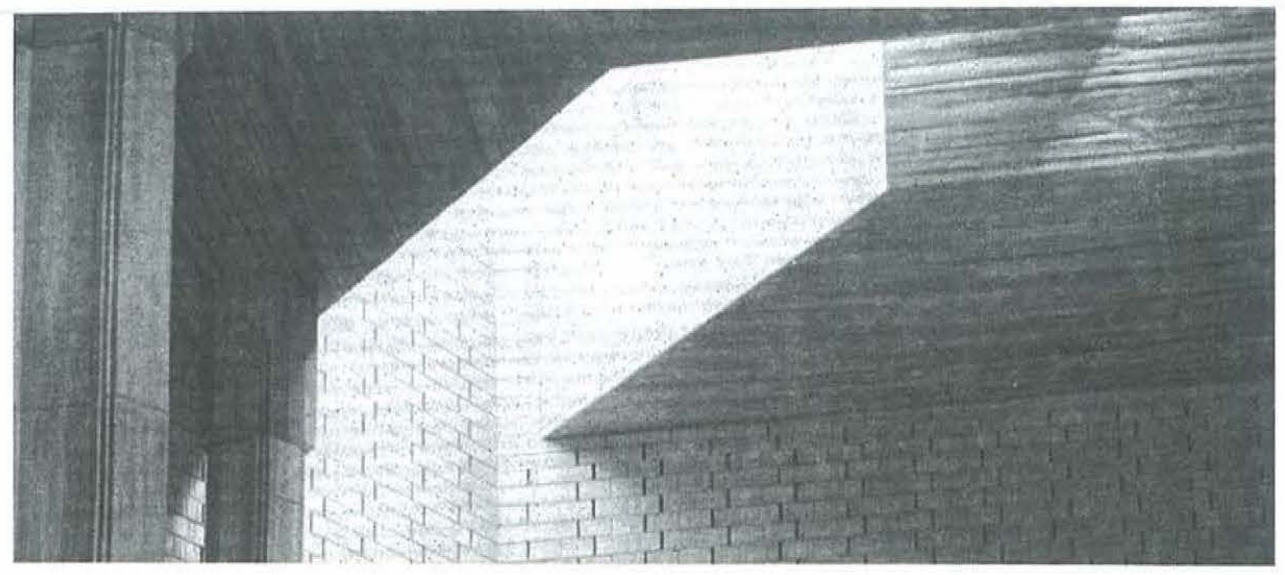

texto cidália silva

Apontamentos sobre a Arquitectura Religiosa do Século XX em Portugal

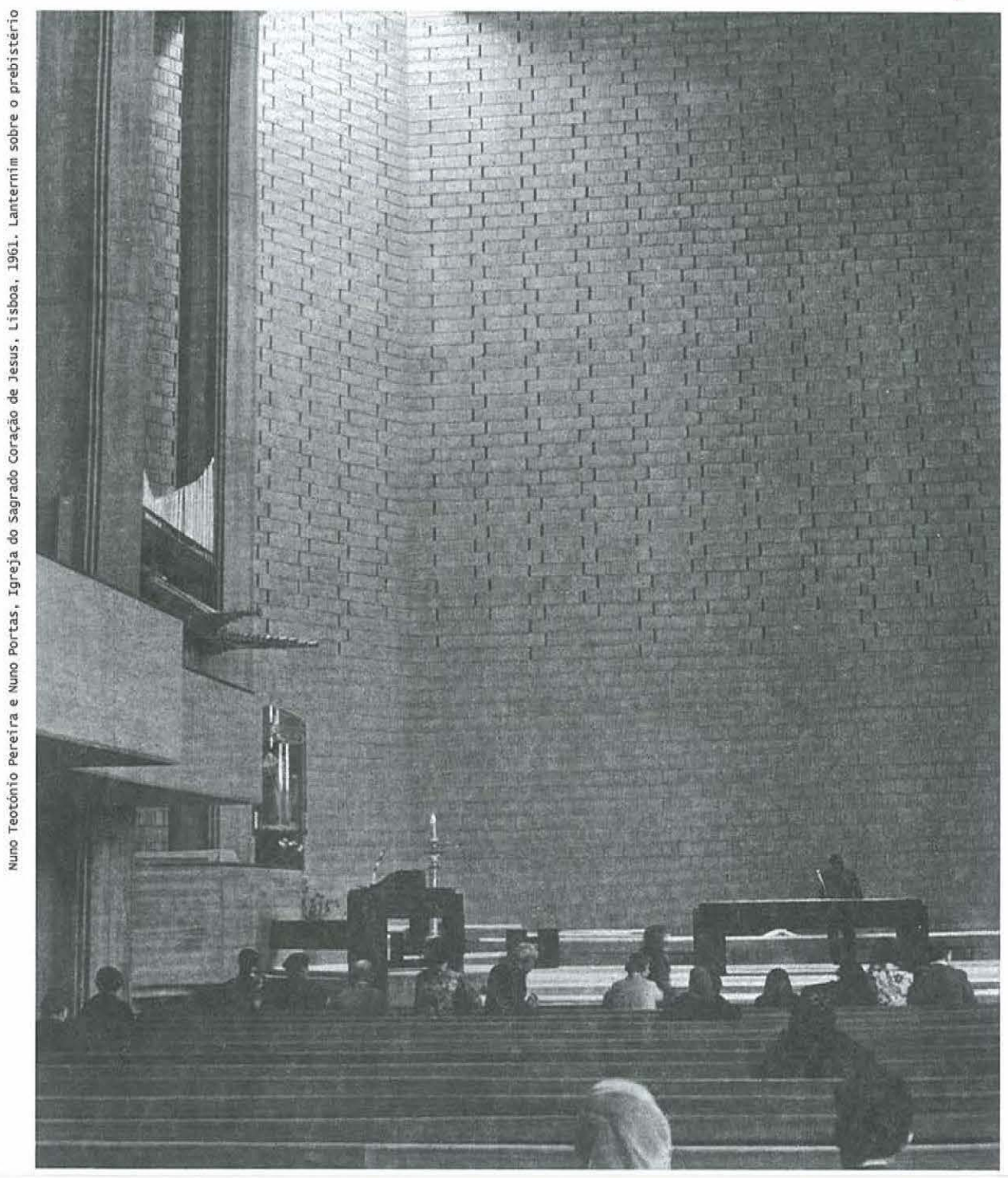


> As igrejas sempre fizeram parte do imaginário arquitectónico colectivo, tiveram continuamente um lugar privilegiado na História da Arquitectura. o património eclesiástico realizou formas que permanecem paradigmáticas. Das basílicas pré-românicas ao esplendor barroco de Borromini e Guarino Guarini, foi construída toda uma arquitectura religiosa que teve consciência da sua época, gerando inúmeras obras de valor, indispensáveis à evolução e ao conhecimento da arte.

> A História da Arquitectura Contemporânea deixou de ser a História da Arquitectura Religiosa, no entanto, foi no séc. Xx que se construíram mais igrejas, decorrentes do crescimento avassalador das cidades. com a secularização e progressiva laicização do universo industrializado, a igreja passou a ocupar um lugar periférico no mundo ocidenta7. Não obstante os disparates evidentes que inspiraram alguns monumentos religiosos realizados no séc. $X X$, não nos podemos esquecer que a arte monumental fez, algumas das mais belas e comoventes expressões plásticas da arquitectura contemporânea. Desde a Capela de Ronchamp de Le Corbusier, às inúmeras igrejas de Rudolf Schwarz, uma série infindável de exemplos poderiam ser citados. Também em Portugal temos obras de arquitectura religiosa de qualidade. É sobre algumas dessas obras que me proponho escrever.

> Estas notas estão baseadas no trabalho realizado no âmbito da Prova Final, da Licenciatura em Arquitectura (1), que teve como objectivo a interpretação dos sucessivos momentos de concepção do espaço religioso no século XX, 
em Portuga1. A estrutura foi desenhada em função de três momentos, a saber: a Igreja de Nossa Senhora de Fátima (1934), em Lisboa, do arquitecto Parda1 Monteiro; a Igreja do Sagrado Coração de Jesus (1961), também em Lisboa, dos arquitectos Teotónio Pereira e Nuno Portas; a Igreja de Santa Maria (1992), em Marco de Canaveses, do arquitecto Álvaro Siza. Recolho nestas páginas o essencial das ideias que me ocorreram enquanto me debrucei sobre esta temática.

[Do vínculo com a história à abstracção da história.]

> A Igreja de Nossa Senhora de Fátima é considerada a primeira obra de arquitectura religiosa moderna no nosso país, sendo um exemplar único até ao final da década de 40 . No entanto, podemos aferir que se trata de uma obra de compromisso entre modernidade e tradição.

\section{A igreja para Pardal Monteiro significa pensar um objecto ideal, um monumento ceTebrativo da Igreja.}

> A igreja para Pardal Monteiro significa pensar um objecto ideal, um monumen-to celebrativo da Igreja, celebrativo não só pela composição arquitectónica, mas também, pela posição urbana, cenográfica, que assume.

> A sua possívet "modernidade" não rompe com os modelos do passado, mas prolongaos e dá-Thes continuidade: na posição de destaque no tecido urbano como remate visual de uma rua; no recur-so a estereótipos formais, como os arcos em "ogiva" justapostos ao espaço paralelepipédico da nave; no entendimento do espaço religioso enquanto espaço hermético, sombrio, que se fecha sobre si próprio; no desenho de uma tipologia de espaço basílical; na autonomia entre cabeceira e nave dos fiéis; na composição simétrica segundo um eixo processional de acesso à igreja (percurso este que nasce da relação axial, urbana, que estabelece com a Av. Barbosa do Bocage) e na procura de monumentalidade ao nível

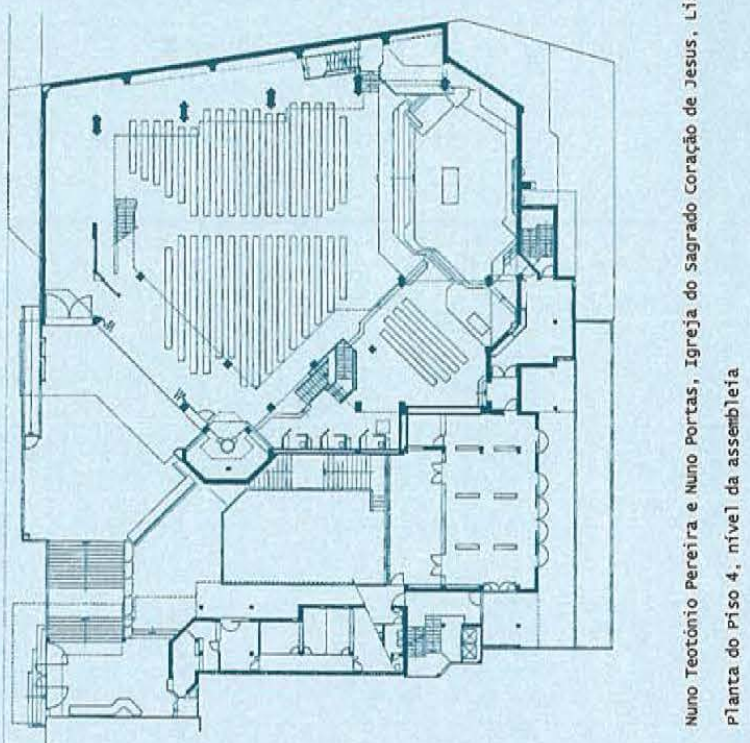


da composição arquitectónica. Mais do que de modernidade podemos constatar que esta obra está, ainda, plenamente vinculada à tradição da arquitectura religiosa.

> A modernidade dos anos 50 anunciada com as igrejas de Penamacor,

> do arquitecto Teotónio Pereira e de Moscavide, do arquitecto António Freitas Lea1 e João Medeiros de A7meida, vai ser outra, essa sim, representando um momento de revisão dos cânones da arquitectura religiosa antecedente e das igrejas revivalistas, suas contemporâneas.

> Se queremos achar um ponto de charneira que inaugura uma nova época, moderna, na arquitectura religiosa portuguesa, vamos encontrá-1o, num acontecimento inaugural que data de 1947. Trata-se do manifesto "Arquitectura Cristã Contemporânea", cujo autor é Nuno Teotónio Pereira. Assim, este arquitecto é além de autor de duas obras de referência na arquitectura religiosa portuguesa, a Igreja das Águas em Penamacor e a Igreja do Sagrado Coração de Jesus, é figura destacada do Movimento de Renovação da Arte Religiosa e é, ainda, e não menos importante, o primeiro autor em Portugal a reclamar publicamente a premência de alterar a situação de declínio na qual se encontrava a arquitectura religiosa. "Com mentira não há Arquitectura digna. E a Arquitectura cristã, pelo seu carácter sagrado, é a que tem maiores exigências de dignidade" (2) .

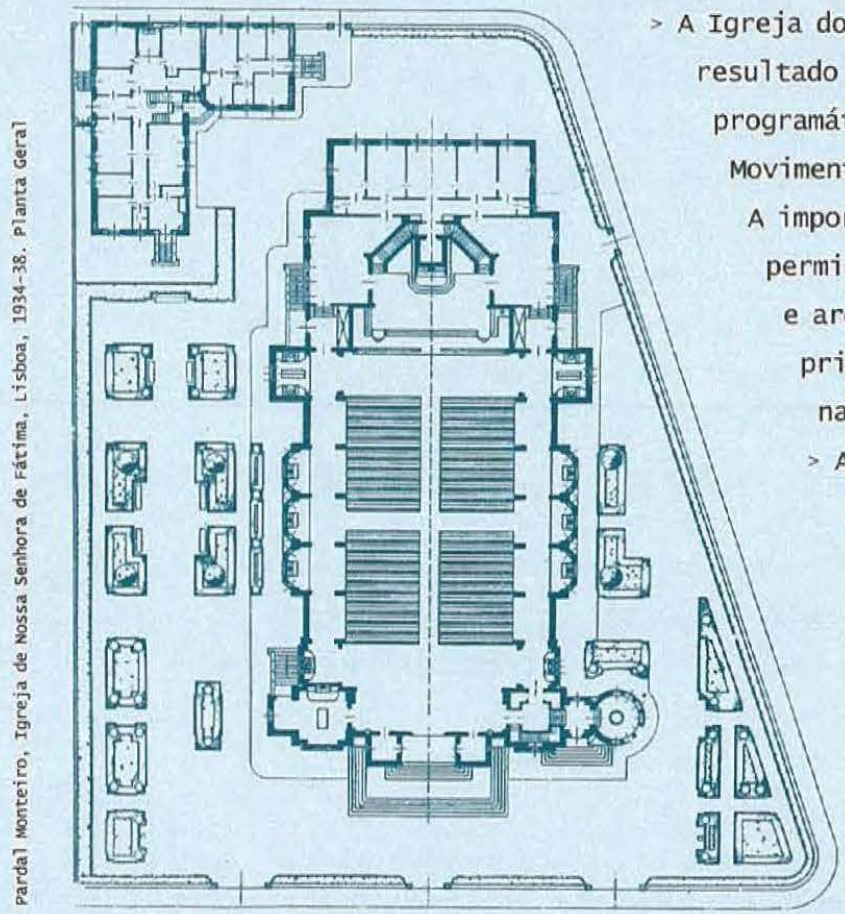

A Igreja do Sagrado Coração de Jesus surge como o tado de um processo de maturação rogramática, antecedido e preparado no seio do Renovação da Arte Religiosa (MRAR) cia do MrAR é indiscutível, porque rmitiu o confronto de ideias entre artistas e arquitectos reunidos no objectivo, primordia1, de "abrir caminho à arte moderna na construção de igrejas" (3).

- A Igreja do Sagrado coração de Jesus propõe uma nova espacialidade que rompe com os modelos tipológicos do passado, o espaço em assembleia: espaço unitário que compreende o presbitério e a assembleia dos fiéis. Por espaço em assembleia consideramos aquele que é desenhado em função da mudança programática introduzida nas igrejas deste período. 
> Pretende-se, ao nível da liturgia, que a comunidade - assembleia de fieis esteja reunida em torno do altar. Desta forma, a anterior dicotomia espacial entre cape1a-mor e nave é abandonada, com a consequente unificação espacia1 das duas zonas. o espaço em assembleia é caracterizado pelo abandono do espaço longitudina1, ałterando-se as proporções do espaço eclesial.

> Para uma interpretação do espaço da Igreja do sagrado coração de Jesus podemos inferir que a ruptura em relação às igrejas do passado se pode sintetizar numa série de binómios, a saber:

monodireccinalidade/pluridireccionalidade; disposição contemplativa/disposição participativa (dinâmica); simetria/assimetria; convergência/policentrismo.

> o valor maior desta igreja reside na capacidade dos autores traduzirem a nova liturgia numa nova arquitectura sacra. o espaço é pensado como tensão entre proporção, Tuz e cor. Dão ênfase, em primeiro lugar, ao desenho do espaço significante e só depois ao desenho dos elementos no espaço, introduzidos em função e ao serviço deste. o carácter de sacralidade é desenhado pela identificação entre espaço religioso/espaço vertical e, também, no tratamento da luz, enfatizando a zona simbolicamente mais importante, na comunidade católica, o presbitério, demonstrando a capacidade que esta igreja tem, enquanto fruto de uma época muito específica e no meio de tanta obra contemporânea, conseguir um lugar de destaque e perenidade no fio da história. Por oposição às igrejas, suas contemporâneas, que reduziam a arquitectura às questöes litúrgicas, ao Funcionalismo Litúrgico, com uma dependência clara do programa, e sem o grau de independência disciplinar intrínseco à arquitectura. ou seja, constituindo-se como obras que podem ser correctas do ponto de vista 1itúrgico, mas pertinentes enquanto obras de arquitectura até que ponto? porque "os espaços transcendem a função, (...) o modo como estão conformados em relação à luz é o problema de todos os edifícios" (4).

> A Igreja de Santa Maria volta a fazer a ponte com a história da arquitectura religiosa. A forma é inspirada no passado, num arquétipo colectivo, resíduo de memória. A mesma história é reinterpretada, metamorfoseada, autonomizando da história construindo história, com o desejo, implícito, de intemporalidade arquitectónica intrínseca à arquitectura sacra do passado.

> A Igreja de Santa Maria é um contratipo em relação às igrejas afiliadas a espaços comunitários. Se as igrejas dos anos 60 recusam a história da arquitectura religiosa, até certo ponto, porque estão absorvidos em questões exteriores à arquitectura (o programa 1itúrgico), nos anos 90, volta-se a colar o fio da história. 
> Manifesta-se o retorno dos valores da memória para materializar uma igreja/espaço arquitectónico capaz de transmitir significados que transcendem o Funcionalismo Litúrgico. Estes princípios não estão presentes, apenas, na Igreja de Santa Maria, mas também na Catedral de Los Angeles (1996-97) de Rafael Moneo. Uma igreja enquanto igreja, criticando as igrejas pós-conciliares laicizadas e que podem facilmente ser confundidas com outro tipo de equipamentos urbanos, teatros, cinemas, ou no limite como casas sem carácter no meio de um tecido urbano igualmente desconsolador. Edifícios que só com um grande esforço podemos denominar de igrejas. Terminologia caduca para uma arquitectura que não consegue esconder a fragi lidade dos seus princípios.

...Terminologia caduca para uma arquitectura que não consegue esconder a fragilidade dos seus princípios.

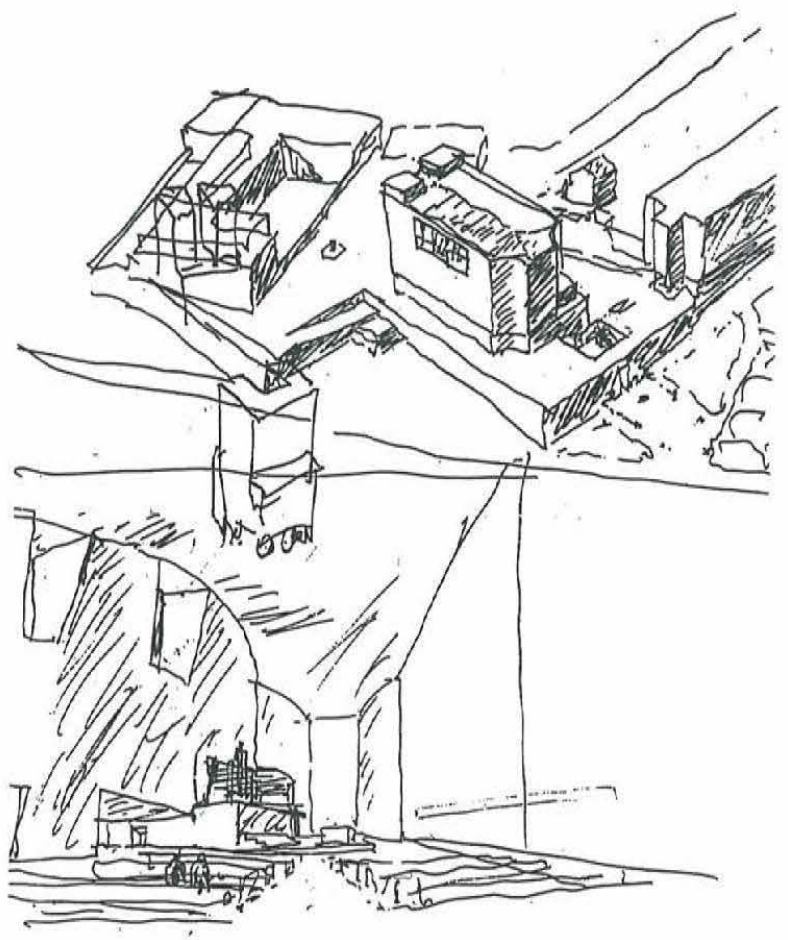


> Parece-nos que uma das questões que ÁTvaro Siza levantou foi: Como é que na contemporaneidade se desenha uma igreja? ou seja, a questão da identidade arquitectónica. É através da reinterpretação da história da arquitectura religiosa, que Álvaro Siza tenta materializar uma igreja que seja uma igreja: no desenho tripartido da fachada principal, as falsas torres; no espaço Tongitudinal de nave única; no eixo processional da igreja, desde o portal até ao altar; no tema do porta1; no desenho da cabeceira. Síntese de grandes temas da arquitectura religiosa sublimados pelo espírito criador, na abstracção de um objecto arquitectónico novo e comovente.

> A Igreja de Santa Maria evita, por um 1ado, o Funcionalismo Litúrgico e, por outro, a tentação de "colocar em cena" o sacro, através da tensão entre dois pólos, que Rudolf Schwarz caracteriza pela passagem, a igreja como puro contentor, e pela permanência, a igreja como monumento. (5)

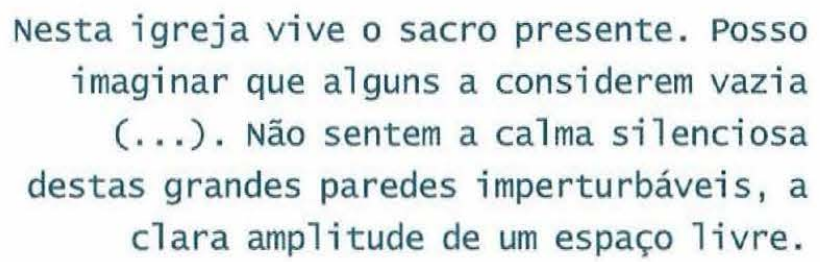

> Através da sua gramática linguística, Álvaro Siza testemunha na Igreja de Santa Maria a capacidade evocativa de um espaço, aparentemente elementar, simples fisicamente, mas complexo e denso de conteúdos na evocação mística. "Nesta igreja vive o sacro presente. Posso imaginar que alguns a considerem vazia $(\ldots)$. Năo sentem a calma silenciosa destas grandes paredes imperturbáveis, a clara amplitude de um espaço livre, o ser puro presente nas coisas formadas simplesmente. Querem que tudo seja cheio de formas, objectos, imagens, assim como não suportam o silêncio" (6).

> A igreja é tão só e apenas, em qualquer obra, o desejo de esculpir um espaço, o desejo de luz, a "suscitadora de todas presenças"(7). "Entendo a luz como a protagonista de um espaço que pretende recuperar o sentido do transcendente e apresentar-se com o sentido do sublime. Daí que para mim a luz seja o veículo que nos há-de conduzir à experiência daquilo a que chamamos sagrado."(8) e C DJ 
1 Silva, cidátía (1999). Três momentos na arquitectura religiosa do século $x x$ em Portugal. Trabalho realizado no âmbito da Prova Final da Licenciatura em Arquitectura, orientado pelo Professor Arquitecto Mário Júlio Teixeira Krùger. Departamento de Arquitectura da Faculdade de Ciências e Tecnologia da Universidade de coimbra. Coimbra.

2 Pereira, Nuno Teotónio (1947), «Arquitectura Cristă contemporânea». ALA da JUC, Janeiro de 1947. (agora in Pereira, Nuno T. Escritos (1947 -1996, selecçăo). col. «Série 2. Argumentos. 7x. FAuP publicaçōes. Porto. 1996. pp. 4-13).

3 Pereira, Nuno Teotónio (1993). «Um testemunho sobre a arquitectura nos anos 50n. Sociedade Nacional de Belas-Artes, Fevereiro de 1993. (agora in Pereira, Nuno T. Escritos (1947-1996, selecção). Col. "Série 2. Argumentos. 7». Faup publicações. Porto. 1996. pp. 254-261).

4 Khan, Louis (1957). "La Arquitectura y la meditada creacion de espacios». Perspecta, $n^{\circ} 4$. (Agora in Norberg-Schulz, C. e Digerud, J. G. (1981) Louis I. Khan, idea e imagem. Xarait Ediciones, Madrid. pp. 60 a 62).

5 Baglione, Chiara (1996). «I 1 mondo sulla soglia. L' architettura sacra di Rudolf Schwarz». CASABELLA. No 640/641. Dezembro de 1996/Janeiro de 1997. Milano. pp. 34 a 39.

6 Guardini, Romano (1930). "Una chiesa di Schwarz" Die Schildgenossen. A. XI. No 3. 1930-1931. (agora in CASABELLA. No 640/641. Dezembro de 1996/Janeiro de 1997. Milano. pp. 40). Esta citação de Romano Guardini aqui apticada à Igreja de Santa Maria era originalmente sobre a Igreja de Aachen de Rudolf schwarz.

7 Khan, Louis (1967), $\propto E$ ] espacio y Tas inspiraciones» in L' architecture d' Aujourd' hui, n' 142 , 1969. Conferencia dada em 14 de Novembro de 1967 no New England Conservatory. (Agora in Norberg-Schulz, C. e Digerud, J. G. (1981) Louis I. Khan, idea e imagem. Xarait Ediciones, Madrid. pp. 95 a 98).

8 Moneo, Rafael (1998). "Catedral de Los Angeles». El Croquis. $n^{\circ}$ 91, 1998. Madrid. pp. 118 a 127.
Arquitectura. $N^{0} 123$. Set. - Out. de 1971. Arquivo Nuno Teotónio Pereira.

Revista oficial do Sindicato Nacional dos Arquitectos. $n^{\circ} 7$. Novembro/Dezembro 1938.

AAW (1998). Igreja de Santa Maria. Marco de Canaveses. Ediçăo/Publicaçăo da Paróquia de Santa Marinha de Fornos e Francisco Guedes. 